\title{
LI. Observations on some of the products obtained by the reaction of nitric acid on alcohol
}

\author{
Golding Bird M.D. F.L.S. G.S.
}

To cite this article: Golding Bird M.D. F.L.S. G.S. (1839) LI. Observations on some of the products obtained by the reaction of nitric acid on alcohol , Philosophical Magazine Series 3, 14:90, 324-330, DOI: 10.1080/14786443908649747

To link to this article: http://dx.doi.org/10.1080/14786443908649747

册 Published online: 01 Jun 2009.

Submit your article to this journal $[\pi$

Џll Article views: 2

Q View related articles $₫$ 
ZI. Obscrvations on some of the Products obtained by the Reaction of Nitric Acid on Alcohol. By Golding Burd, M.D., F.L.S., G.S., \&c. Lecturer on Natural Philosophy at Guy's Hospital.*

FEW subjects connected with organic chemistry have engaged more the attention of chemists than the action of nitric acid on alcohol, from the discovery of hyponitrous æther by Navier, up to the present moment. The composition of what bas been long termed sweet spirits of nitre, is now well determined, and no doubt exists of its being a combination of hyponitrous acid with æther ( $4 \mathrm{C} .5 \mathrm{H} 1 \mathrm{O}+\mathrm{N} 3 \mathrm{O}$ ). Some of the products formed simultaneously with this æether have been less completely and satisfactorily understood; chemists have however for the mrost part agreed in stating malic, oxalic, acetic, and carbonic acids to be among the new-formed products, togrether with a substance mentioned by Thenard as "très facile à charbonner." Taking advantage of the residue left in the retort after the preparation of $\mathrm{sp}$. æeth. nitrici on the large scale, I submitted it to examination and obtained some interesting and unexpected results. In the pharmaceutical laboratory of Guy's Hospital, this æther is prepared by distilling in a sand-heat two gallons of alcohol of about 850 , and 24 ounces of nitric acid of $1 \cdot 50$, the operation being stopped when about $3 \frac{1}{2}$ pints of fluid are left in the retort. This fluid is straw-coloured, varying in specific gravity from 1.03 to $1 \cdot 06$, strongly acid, and possessing the agreeable odour of hyponitrous æther. When carefully neutralized by a solution of potass it assumed a rich orange-brown tint, and became slightly turbid; the fluid thus saturated precipitated acetate of lead most copiously, but did not affect the limpidity of lime-water or a solution of chloride of calcium, and hence did not contain oxalic acid, although this substance is generally stated to be present in the residue of the distillation. The most remarkable phænomenon, however, occurred when some of this carefully neutralized fluid was exposed to heat in a porcelain bason: as soon as it became warm the colour deepened in tint, in a short time becoming of a rich chocolate brown; a most disagreeable and penetrating odour, something like that of boiling soap, being evolved : in this experiment the temperature of the fluid did not exceed $160^{\circ}$ Fahr., the change commencing at $115^{\circ}$ Fàhr., and went on briskly at $120^{\circ}$ Fabr. For the purpose of determining the

* Read before the Chemical Section of the British Association, at Newcastle-on-'Tyne, August $18: 38$ : and communicated by the Auther. 
nature of the substance concerned in these phanomena the following experiments were performed.

A. About a pint of the acid yellow fluid remaining after making sp. æth. nit. was submitted to distillation in a glass retort, the temperature applied being just sufficient to keep up gentle ebullition: the first few ounces of fluid that distilled over possessed the flavour and odour of hyponitrons æther, and underwent no change of colour by the addition of a solution of potass; after these had passed over and the receiver been changed, distillation was carried on until orange-coloured fumes appeared in the retort; the fluid collected in the receiver was then removed: its specific gravity was 0.980: it reddened litmus paper, possessed an odour of rether mixed with one so irritating that it produced smarting of the nostrils and eves with copious lacrymation; its flavour was at first grateful, rapidly however becoming acrid like cayenne pepper, leaving a burning sensation in the mouth and fauces.

B. To this distilled fluid a solution of pure potass, of spec. gr. 1.06, was added; the mixture instantly assumed a fine orange colour, which on the application of a gentle heat deepened in tint, a strong penetrating "soapy" odour being evolved.

C. The excess of acid in the distilled fluid was next neutratized with ammonia, and a solution of nitrate of silver added; a copious white precipitate occurred, which on being warmed over a spirit lamp became dark and converted into reduced silver, giving the fluid a bluish tint when viewed by transmitted light.

D. From these experiments $I$ at first suspected the presence of formic acid, as this (as is well known) readily reduces silver-salts, although the peculiar action of potass is by no means reconcileable with the known properties of that acid. To ascertain whether this acid was really present I neutralized exactly some of the distilled fluid with a weak solution of potass and evaporated it over a vapour-bath to dryness; a nearly black residue, containing a few acicular crystals, resulted. This was placed in a retort mixed with sulphuric acid, and distilled, but not a trace of either formic or acetic acid could be detected in the distilled fluid, which appeared to contain a small quantity of nitric acid. lt hence appeared evident, that formic acid could not be the reducing agent in Exp. C, whilst from this circumstance, from the action of potass, and the peculiar odour, I was led to suspect the presence of aldehyd.

E. Some of the distilled fluid was neutralized with potass and warmed; when it had assumed the orange-brown tint it 
was poured into some very dilute sulphuric acid; a yellow powdery deposit fell; this on the application of heat collected into a resinoid mass, soluble with tolerable readiness in alcohol and æther, resembling in its properties the resin of aldebyd described by Liebig in the second number of his excellent Handwörterbuch der Chemie. This circumstance, together with reduction of metallic salts, and the peculiar irritating soap-like odour, left scarcely a doubt of the presence of aldehyd. It now became an interesting question to determine the conditions of the formation of this substance, particularly as the fluid from which this aldehydiferous fluid had been separated by distillation copiously precipitated salts of lime after neutralization by ammonia, indicating the presence of oxalic acid, which as I have already mentioned was absent in the residual fluid previons to this second distillation, and consequently must be considered as a secondary product, resulting from the reaction of nitric acid on some substance formed in the earlier stage of the operation.

F. Some hyponitrous æether was then prepared without heat, by IOr. Black's process, by allowing nitric acid and alcohol to react on each other through a stratum of water in a cylindrical vessel : after the action had continued for two days, some of the lighter part of the fluid was decanted into a retort; it was strongly acid, but smelt agreeably of nitrous æther. On submitting it to distillation a colourless fluid was collected in the receiver; that resulting from the earlier part of the distillation was not at all acrid, nor was it altered by a solution of potass; whilst that which came over last was intensely acrid in flavoul, reduced salts of silver after the addition of ammonia, and underwent those changes with weak solutions of potass which characterize aldehydiferous fluids. 'This experiment was by no means satisfactory as showing the formation of aldehyd by the action of nitric acid on alcohol in the cold, in consequence of the acidity of the fluid previous to distillation; enough nitric acid being probably present in the retort to produce this peculiar substance by the reaction on alcohol or ather on the application of heat. To determine this fact with greater accuracy, some of the acid ather prepared by Dr. Black's process was digested with protoxide of lead and then distilled over some of this oxide: the fluid in the receiver was very mild in flavour, of spec. gr. 0.926 , and underwent no change in colour by the addition of alkaline solutions : it was also destitute of action on salts of silver; hence the absence of aldehyd may be safely inferred. From this circumstance we may conclude that this curious substance is by no means a necessary result of the action of nitric acid on alcohol 
during the formation of hyponitrous æther. The acid fluid left in the cylinder in Dr. Black's process, after these two portions of æether had been decanted, was set aside very loosely covered with a glass plate. In the course of a few days it evolved a pungent odour of acetic acid; it was neutralized with carbonate of soda, and evaporated to a small bulk; numerous crystals of nitre appeared; the supernatant fluid was evaporated to dryness : a crystalline and exceedingly deliquescent mass resulted; this when treated with sulphuric acid evolved copious fumes of acetic acid.

I next turned my attention to the non-volatile products resulting from the action of nitric acid on alcohol. Some of the residual fluid in the retort, after preparing sp. æth. nit. on the large scale, of sp. gr. 1·06, was carefully saturated with carbonate of soda: the neutral fluid after being warned to get rid of carbonic acid did not trouble solutions of chloride of calcium, and was therefore free from oxalic acid; a solution of acetate of lead was added until no further troubling ensued; the copious precipitate that fell was collected, well washed, and drained on a filter. This substance was diffused through water, and submitted for twelve hours to a current of sulphuretted hydrogen until no more gas was taken up. The mixture was boiled and filtered. The colourless fluid thus obtained was acid, but by very careful evaporation did not evince any tendency to crystallize : it was divided into two portions; one was carefully neutralized by ammonia and the unsaturated portion added. By very careful evaporation over a vapour-bath delicate acicular crystals of an acid ammoniacal salt were obtained. These crystals did not contain malic acid, the presence of which I had expected, for the precipitate their aqueous solution yielded with salts of lead did not dissolve in any appreciable quantity in hot water, nor did it fuse at $212^{\circ}$. As far as $I$ have examined the acid combined with the ammonia in these crystals, I am disposed to regard it as that which has long been confounded with malic acid, viz. oxal-bydric acid, a substance produced by the action of nitric acid on many of the products of organization, often simultaneously with oxalic acid $(4, \mathrm{C} 3 \mathrm{H} 6 \mathrm{O})=\overline{4 \mathrm{C}, 6 \mathrm{O}}+3 \mathrm{H}$.

A fresh portion of the fluid left after the distillation of nitrous æether was evaporated slowly to a syrupy consistence; nitrous acid fumes appeared in abundance: the whole being allowed to cool deposited in a few hours numerous crystals, which were readily distinguished as those of oxalic acid. The mother liquor was decanted, and submitted to fresh evaporation and set aside : by cooling, delicate foliaceous crystals, possessing the pearly lustre of cholesterine, appeared in the fluid; 
these were separated and drained on filtering paper: on being subsequently examined, they also proved to be oxalic acid like the first formed crystals, from which they altogether differed in their physical characters. I am quite unable to account for the curious forms assumed by the second crop of oxalic acid crystals; not having submitted them to analysis I cannot state whether they contained the same quantity of water of crystallization as those possessing the ordinary crystalline form.

Having thus shown that oxalic acid is not a constant product during the preparation of nitrous æether, at least in the earlier stages of the operation, I was anxious to ascertain whether the evolution of aldehyd and formation of oxalic acid bore anything like a mutual relation. For this purpose the following experiment was performed. A quantity of the fluid left in the retort after the preparation of sp. æth. nitrici was placed in a tubulated retort, and a quilled receiver was so adapted as to allow a receiving bottle placed beneath to be changed and removed at will. A sand-heat was then applied and distillation commenced : when about one fourth of the fluid had passed over, the receiving bottle was charged and the fluid examined; it was colourless, aromatic, of sp. gr. 0.861 , was unaffected or nearly so by the addition of alkaline solutions, and appeared to be merely an alcoholic solution of hyponitrous æther which had not been completely removed by the operation on the large scale. Some of the fluid in the retort was removed and examined; it was nearly totally free from oxalic acid, and appeared to contain among new products only the oxal-hydric acid. Heat was again applied to the retort, and about a third of the remaining fluid was distilled over; this was of sp. gr. 0.872, exceedingly acrid, like capsicum in flavour, acid, and assumed a deep orange tint by the addition of solution of potass even in the cold; this increased by heat, and the subsequent addition of dilute sulphuric acid produced a copious deposition of the resin of aldehyd. The fluid in the retort contained a large quantity of oxalic acid, formed probably by the reaction of the free nitric acid present upon the oxal-hydric acid formed in the first stage of the operation. Upon a third application of heat distillation was carried on until red fumes appeared; the fluid in the receiving bottle was of sp. gr. 0.972 , very acid, scarcely contained any æther, and much less aldehyd than the portion previously distilled, as it was merely tinged yellow by potass : the fluid left in the retort was so loaded with oxalic acid that it crystallized by cooling.

From these experiments, one fact at least of pharmaceutical 
importance may be inferred, viz. that in preparing the sp. æth. nitrici for medical uses, the distillation ought to be stopped when oxalic acid appears in the retort, to avoid the presence of aldehyd in the distilled fuid, and consequently that the limitations with regard to the quantity of product obtained, mentioned in the Pharmacopoia, should be strictly attended to, as the presence of so pungent and irritating a fluid as aldehyd in the sp. æth. nit. of the shops, cannot but interfere considerably with the cooling febrifuge uses of the latter. I may remark, that as in the preparation of this æether on the large scale it is of importance to the manufacturer to obtain as large an amount of product as possible, we find, as might be expected, traces of aldehyd in most commercial specimens of the :xther, which indeed is indebted to it for that pungent acrid flavour it so frequently possesses. If the directions of the London Pharmacopœia be observed, the product is always free from aldehyd; this I have verified in several instances in numerous specimens prepared in the pharmaceutical laboratory of Guy's Hospital, as well as in that of my friend Mr. R. Phillips, of St. Thomas's Hospital.

In conclusion, I may be permitted to submit the following as the inferences deducible from the foregoing observations:

1. That in the preparation of sp. æth. nitrici, as long as the latter with alcohol only distils over, no oxalic acid is produced, an acid which appears to be identical with the oxalhydric only appearing in the retort.

2. That on continuing the distillation beyond this point, the free nitric acid in the retort reacts on the oxalhydric and produces oxalic acid.

3. That in the action of nitric acid on alcohol in the cold as in Dr. Black's process for the formation of hyponitrous æther, acetic acid is copiously produced, instead of, or in addition to, oxalhydric acid.

4. That aldehyd (as has been before shown by chemists) is produced by the action of nitric acid on alcohol, but that it is not formed in any quantity, or at least does not appear in the distilled fluid, until the formation of hyponitrous rether has nearly or altogether ceased.

5. That the production of aldehyd and oxalic acid are nearly simultaneous, and that both these appear to result from secondary action of nitric acid upon products formed in the early stages of the operation.

6. That the "crystals of Hierne" formed when distillation is carried on until red fumes appear are oxalic acid, notwithstanding their remakable micaceous form; and that the sub- 
stance très facile à charbonner, mentioned by Thenard, is probably aldehyd, which from its behaviour towards alkalis might apparently merit that character.

LII. Answer to the Objections published against a general Theory of the Visual Appearances which arise from the Contemplation of Coloured Objects. By J. Plateau, Professor at the University of Ghent.

\section{To the Editors of the Philosophical Magazine and Journal. Gentlemen, Ghent, April 15, 1837. $\dagger$}

I HAVE the honour to transmit you herewith an article 1 which I should thank you to insert in your Journal. Although the main object of this paper is not to make known new facts, you are weil aware that theoretical discussions are not void of interest with regard to science. Besides, when a theory is attacked, it is naturally to the organs of scientific publicity that the office belongs to furnish the author of that theory with the means of defending his ideas. As it was in England that the principal objections against my statements appeared, and as a part of those objections were published in your Journal; lastly, as my article contains a mere scientific defence, I make no doubt, Gentlemen, that you will willingly devote your pages to it, and do me the favour to insert it in your next Number.

$$
\begin{aligned}
& \text { I remain, Gentlemen, yours, \&c., } \\
& \text { JH. PLATEAU, } \\
& \text { Professor at the University of Ghent. }
\end{aligned}
$$

In publishing my theory on the visual appearances which succeed the contemplation of coloured objects, and on those which manifest themselves during that contemplation $\ddagger$, I conceived that if this work deserved any attention, it was principally on account of the generality and simplicity of the point of view under which I have united four different classes of phænomena whose affinity to each other has not been acknowledged; namely, the duration of impressions on the retina, the

$\uparrow$ This communication, as I subsequently learnt from M. Platean, was forwarded from Ghent at the date which it bears, and having, after being long given up for lost, at length come to hand through some unknown channel, it is now published without further delay.-R. $T$.

† See An. de Chim. et de Physique of Messrs. Gay-Lussac and Arago, August 1833, page 386, and April 1835, page 337. Supplement to the Treatise on Light of Sir J. Herschel, by M. Quetelet, page 515. Memoirs of the Academy of Brussels, tom. viii. 